\title{
Mutations in the filaggrin gene and food allergy
}

\author{
Anna Ogrodowczyk, Lidia Markiewicz, Barbara Wróblewska \\ Institute of Animal Reproduction and Food Research, Polish Academy of Sciences, Olsztyn, Poland
}

Prz Gastroenterol 2014; 9 (4): 200-207

DOI: 10.5114/pg.2014.45100

Key words: food allergy, filaggrin, gene mutations.

Address for correspondence: Anna Ogrodowczyk MSc, Institute of Animal Reproduction and Food Research, Polish Academy of Sciences, 10 J. Tuwima St, 10-784 Olsztyn, Poland, phone: +48 506286 446, e-mail: ania.ogrodowczyk@o2.pl

\begin{abstract}
The results of long-term epidemiological studies show that the number of people suffering from allergic diseases, especially from food allergies and atopic dermatitis (AD), is still increasing. Although the research thus far has been conducted mainly in Europe, North America, and Asia, there are also data appearing from the first studies in that field among the African population. This may indicate the importance of the problem of allergic diseases. The discovery that loss-of-function mutations in the gene coding filaggrin (FLG) are the cause of ichthyosis vulgaris marked a significant breakthrough in understanding the pathogenesis of allergic diseases. The presence of mutations in the filaggrin gene is also an important factor that predisposes to such allergic diseases as: allergic rhinitis, atopic dermatitis, atopic asthma, and food allergy. So far, over 40 loss-of-function mutations and numerous silent mutations in filaggrin have been discovered.
\end{abstract}

\section{Progression of allergic diseases}

Allergic diseases are a complex of diseases resulting from the contact of an allergic organism with allergens, which are substances that the organism recognises as strangers and which cause oversensitive reaction of the immune system. The most common allergic diseases include the following: allergic rhinitis (AR), often diagnosed together with atopic asthma (AA); atopic dermatitis (AD), as well as inhalatory allergy (IA); contact allergy (CA); and food allergy (FA). In spite of dynamic progress in diagnosis, prophylactics, and treatment of those diseases within the last 30 years, a constant increase in people suffering from them is still evident. The amount of patients with symptoms of allergic diseases has prompted the world society to intensify their epidemiological research.

The results of long-term research, i.e. "International Study of Asthma and Allergy in Childhood" (ISAAC) [1], "The European Community Respiratory Health Survey" (ECRHS) [2], and "The Epidemiology of Allergic Diseases in Poland" (EADP) [3], indicate an expansion of allergic diseases. It has been estimated that $10 \%$ to $30 \%$ of the world's population suffers from allergic diseases, depending on their form. This group comprises more than 80 million people in Europe alone. In Poland, the problem affects more than $40 \%$ of the population. The prognosis for 2015 is that every second European will be affected by an allergy. Scientists stress that the correlation between the incidence of allergic diseases, the geographic region, and the season is decreasing; however, the correlation between the diseases, lifestyle, and hygiene is on the increase. A lot of attention is also being paid to the role of genetic factors in the development of allergic diseases as well as to the interactions between genetic and environmental factors.

\section{Genetic origin of allergic diseases}

The genes responsible for the pathogenesis of allergic diseases can be divided into four basic groups with respect to the different mechanisms that they take part in (Figure 1). The first group, the most numerous and diversified, is made up of the genes that regulate functioning of the immune system in an allergic inflammation. That group includes transcription factors that regulate Th1/Th2 cell differentiation, e.g. IL-13, IL-4 and STAT6 [4], as well as the T-box transcription factor that is expressed in the T lymphocyte cells (TBX21 gene variants) [5]. Moreover, the first group includes genes of such factors as IRAK-M and PHF11 that may also regulate inflammatory processes in the organs manifesting allergic diseases (e.g. respiratory tract, skin, nose) [6] as well as the genes the products of which are responsible 


\begin{tabular}{|c|c|}
\hline $\begin{array}{l}\qquad 1^{\text {st }} \text { Group of genes } \\
\text { REGULATORS OF ALLERGIC INFLAMMATION } \\
\text { - Transcription factors that regulate the Th1/Th2 cell } \\
\text { differentiation, e.g.: HLA-G, GATA } 3 \\
\text { - The effector gene, e.g.: STAT-6, TBX21 } \\
\text { - Regulators of inflammatory processes in the organs } \\
\text { manifesting allergic diseases } \\
\text { - Genes responsible for regulating the eosinophil level in the } \\
\text { blood, e.g.: IL1RL1, IL-33, MYB, WDR36 }\end{array}$ & $\begin{array}{l}2^{\text {nd }} \text { Group of genes } \\
\text { RELATED TO FORMING THE FIRST LINE OF DEFENCE } \\
\text { AGAINST PATHOGENS } \\
\text { - Genes coding the ingredients of non-specific immune } \\
\text { response i.e.: the genes coding CD14 and TRL4 } \\
\text { - The polymorphic gene of glutathione S-transferase i.e.: } \\
\text { GSTM1, GSTM2, GSTM3, GSTM5, GSTT1, GSTP1 }\end{array}$ \\
\hline \multicolumn{2}{|c|}{$\begin{array}{l}\text { Products of expresion of numerous genes may } \\
\text { participate in the disease pathomechanism on } \\
\text { many levels e.g.: the product of IL-13-coding gene }\end{array}$} \\
\hline $\begin{array}{l}3^{\text {rd }} \text { Group of genes } \\
\text { - ADENES OF CHRONIC TISSUE INFLAMMATORY RESPONSE } \\
\text { muscles) } \\
\text { - PDE4D (expressed in cells of the smooth muscles and cells } \\
\text { affected by an inflammations) } \\
\text { - COL29A1 (coding collagen, expressed in the skin and related } \\
\text { to atopic dermatitis) }\end{array}$ & $\begin{array}{l}\qquad 4^{\text {th }} \text { Group of genes } \\
\text { THE EPIDERMIS BARRIER FUNCTION } \\
\text { - The gene that codes filaggrin (FLG) } \\
\text { - Chitinase-coding genes i.e.: YKL-40 and AMCase }\end{array}$ \\
\hline
\end{tabular}

Figure 1. Genes role in pathogenesis of allergic diseases

for regulating the eosinophil level in the blood (IL1RL1, IL-33, MYB, WDR36) [7].

The second group is related to forming the first line of defence against pathogens in the organism. That group includes the genes coding the ingredients of non-specific immune response, i.e. the genes coding CD14 and TRL4, which participate in the reaction with lipopolysaccharides (LPS) in the cell wall of a bacterium [8]. That group also includes genes coding the enzymes that take part in the organism detoxification, e.g. the gene of glutathione S-transferase that levels the results of the oxidative stress resulting from exposition to air pollution or tobacco smoke [9].

The third group is made up of genes connected with the response to chronic tissue inflammation, such as ADAM33 (expressed in fibroblasts and cells of the smooth muscles) [10], PDE4D (expressed in cells of the smooth muscles and cells affected by inflammation) [11], and COL29A1 (coding collagen, expressed in the skin and related to atopic dermatitis) [12]. It should also be mentioned that products of numerous genes may participate in the disease pathomechanism on many levels, e.g. the product of the IL-13-coding gene regulates occurrences of atopic allergy by switching the class and producing IgE, has a direct influence on the respiratory tract epithelium and the mesenchyme, and also induces metaplasia of goblet cells and proliferation of fibroblasts [13].

The fourth group of genes is responsible for maintaining the epithelium integrity. It has its share in producing the surface barrier of the mucous membrane and in creating a signal stimulating the immune sys- tem to a response to irritation factors originating from the environment. A crucial role in the course of allergic diseases is played by the chitinase-coding genes: YKL-40 [14] and AMCase. Those genes play an important role in modulating the inflammation. Their increased expression also takes place in epithelium cells and activated macrophages in patients suffering from asthma [15]. The gene that codes filaggrin (FLG) is the next one, the polymorphism of which results in disorders to the epithelium continuity as an anatomic and functional barrier. There have been 40 mutations in that gene identified so far. In the European and American populations the most common nonsense mutations of the FLG gene include 2282del4 and R501X. There is some intensive research carried out into mutation variants in the filaggrin gene and their connection with increased susceptibility to diseases of an allergic origin. So far, a correlation between a mutation in the FLG gene and occurrences of such diseases as AD [16], AA, and AR has been confirmed. It has also been observed that their presence increases the probability of inhalatory allergy [17], contact allergy (e.g. to nickel) [18], and allergies caused by food allergens (e.g. peanut allergens) [19].

\section{Formation, structure and functions of filaggrin}

Filaggrin is a base, histidine-rich, and insoluble protein with molecular mass of 35-37 kDa. Its name refers to its ability to aggregate keratin filaments (filaggrin = filament aggregation protein). Together with keratin, it makes up about $80-90 \%$ of protein ingredients in the epidermis. Filaggrin is responsible for the proper forma- 
tion of the cornified layer in the skin, which protects from loss of moisture and forms a barrier for allergens, toxins, and microbes [20]. Products of filaggrin proteolysis (hygroscopic acids, i.e. urocanic acid and pyrrolidone carboxylic acid) are included in the natural moisturising factor (NMF) in the skin. Filaggrin is produced from profilaggrin, a precursor that is included in keratohyalin granules in the granular layer. The presence of profilaggrin polymers has been observed as early as in the $15^{\text {th }}$ week of the human foetal life. Until the $21^{\text {st }}$ week, keratohyalin granules are also present.

Profilaggrin is a highly phosphorylated, inactive polypeptide with a molecular mass of about $500 \mathrm{kD}$. It consists of an N-terminus domain S100 capable of binding calcium, domain B placed next to domain S100, and 10-12 filaggrin monomers arranged in series. Ten highly homologous monomeric units of human filaggrin have been identified. Each repetition of the monomer is built of 324 amino acids and is separated from the other repetitions by a joining region made of 19 amino acids. The number of filaggrin monomeric units depends on the filaggrin gene allele. When keratinocytes move towards the cornified epidermis layer, profilaggrin is subjected to a post-translational modification, which includes a proteolytic digestion by caspase-14 and dephosphorylation of the formed filaggrin units. The filaggrin molecules aggregate keratin filaments and lead to collapsing and flattening of keratinocyte cells and forming a non-nucleated corneocyte scale.

The filaggrin (FLG) coding gene is localised on the short arm in chromosome 1: in region 1q21 included in the epidermal differentiation complex (EDC) that consists of 27 genes. The FLG includes about 25,000 base pairs (kbp) and consists of three exons. Exon 1 (15 bp) includes a 5' sequence not subjected to translation (UTR - un-translated region). The translation-initiating codon is localised in Exon 2. Exon 3 holds localisations of the majority of the $\mathrm{C}$ - and $\mathrm{N}$-terminus domains as well as all repetitions of filaggrin units [21].

\section{Mutations of the FLG gene}

The issue of a factor that disturbs filaggrin synthesis in the epidermis had posed a problem since a lowered level of filaggrin in the course of ichthyosis vulgaris was first observed via immunoblotting [22]. Some similar observations were made as a result of ELISA examinations and from studying mRNA micro-arrays in patients with $A D$ [23]. The structure of the filaggrin gene, due to its large size and changeable number of filaggrin-coding subunits arranged in series, remained unknown for a long time. It was the development of technology in molecular biology that finally allowed for its sequencing. The discovery, made by Smith's team in
2006, of point nonsense mutations R501X and E2422X within that gene, which resulted in the premature termination of translation within the first filaggrin subunit, was a breakthrough in understanding the role of the epidermal barrier in the pathomechanism of skin and allergic diseases [24]. So far, there have been over 40 mutations reported, including some resulting in a loss of function and silent ones. The FLG gene is inherited in an autosomal recessive way. Homozygotes with a mutation in that gene manifest an acute form of atopy. Heterozygotes may be its asymptomatic carriers or manifest a benign or moderate form of atopy $[25,26]$. Each examined population may have a unique set of FLG mutations [27].

\section{The role of FLG gene mutations in the pathomechanism of allergic diseases and in the context of the atopic march}

According to previously quoted reports, no filaggrin expression has been shown so far in the mucous membrane of the digestive tract or in the lower respiratory tract $[28,29]$. Nevertheless, some suggestions of a connection between impairments to the epidermal barrier structure and the development of allergic diseases other than AD, i.e. asthma, AR, or food allergy, have appeared in publications that describe experiments on mouse models [30]. The results of that research have confirmed that impairments to the epidermal barrier function increase the risk of developing a systemic allergic response, increase the general lgE titre, and lead to bronchial overactivity. The results of some clinical and control studies that focused on searching for a correlation between the presence and the type of a mutation in the filaggrin gene and the risk of allergic disease have also confirmed the existence of such a connection [31, 32]. The results of the cohort ALSPAC [33] and ISAAC II [34, 35] studies confirm the essence of a connection between mutations in the filaggrin gene and developing asthma in patients suffering from AD at the same time or in the past. Marenholz et al. point out a high degree of predictability of AA in patients with $A D$, based on the obtained positive results in tests for mutations in the filaggrin gene. The study included 871 children in whom a correlation has been shown between FA and AD diagnosed within the first three years of life and an increased risk of asthma symptoms in the further ontogenesis [36].

As the course of allergic diseases is characterised to some extent by sequentiality and a progression of symptoms, scientists also examine the significance of the atopic march as a predictive factor for allergic diseases. Current views on the allergic march or a subsequent coexistence of such diseases as FA, AD, AA, and 
$A R$ are varied. Supporters of the atopic march theory in its classic model view $A F$ and $A D$ with the strongest symptoms within the first 2 years of life as the diseases initiating the march. According to that theory, the FA incidence, reaching about $10 \%$ of cases within the first year of life, decreases to $3 \%$ in pre-school age. At the same time, the risk of inhalatory allergies increases to $8 \%$ in that period [37]. The main risk factors for the development of AA and AR include an IgE-dependent allergy and intensification of AD. Nearly $70 \%$ of patients with acute $A D$ develop asthma, while only $20-30 \%$ of patients have its benign form, and only about $8 \%$ in the general population. Other allergic diseases, e.g. AR with a tendency to turn into AA, may also be the first symptoms of the allergic march. There are also numerous alternative occurrence sequences for atopic diseases described in the course of the march. As provided by various sources, $15-50 \%$ of AD cases are preceded by occurrences of asthma and AR [38]. In spite of discrepancies in opinions on the atopic march, a connection has been shown between mutations in the filaggrin gene and an increased risk of $A D$ development and the coexistent AA [39].

Based on the results of the research up to now, it has not been possible to trace down completely a molecular mechanism of the development and course of allergic diseases that include organs in which no presence of filaggrin was noted. However, several already known mechanisms seem to explain the connection between those diseases and mutations in the FLG gene. The mechanism of allergy development resulting from a transdermal sensitivity involving a subpopulation of Th17 cells is one of them [40]. In experiments on mouse models with disturbed filaggrin expression in the skin exposed to ovalbumin proteins, an increased expression of inflammatory cytokines of the Th2 profile (acute phase) or cytokines of the Th1 profile (chronic phase), as well as a cellular infiltration of T cells and eosinophils, has been observed. It has also been noted that induced bronchia over-reactivity occurred, resulting from a stimulating influence of those processes on the influx of neutrophils to the respiratory tract. Thus, IL-17 may be a key marker indicating the connection between the epidermal barrier damaged by mutations in the filaggrin gene and allergic diseases, and may also account for their coexistence [41].

\section{Food allergy process}

The term food allergy (FA) is applied to an undesired reaction upon consuming food, resulting from an excessive reaction of the immune system. About $90 \%$ of allergic reactions to food are caused by consuming such foods as cow's milk, eggs, nuts, soy, wheat, fish, and seafood. The human organism has its first contact with the protein antigens of cow's milk as early as in infancy. The occurrence of IgE-dependent allergic reaction to cow's milk proteins in the initial phase of life increase the risk of developing a fixed form of the allergy and may contribute to the development of food or contact allergic reactions to other types food. There are disturbances to the immune system of the IgE-dependent, IgE-independent (cellular), and mixed character distinguished in the course of the food allergy. Direct contact of the organism with the antigens happens via the skin and mucous membranes that cover the digestive and respiratory systems, the conjunctiva, the genitourinary system, and others. Due to their large surface and delicate structure, the mucous membranes are the place where most inflammations are initiated [42]. A dominant role in triggering the food allergy is played by the mucous membrane in the digestive tract and the gut-associated lymphoid tissue (GALT) that accounts for over $70 \%$ of lymphocytes in the whole immune system.

\section{The significance of disorders of the epidermis barrier function in triggering a food allergy}

Often the first symptoms of a food allergy occur before the product containing the allergen is introduced to the diet consciously, which makes the diagnosis, treatment, and, in particular, possible prophylaxis of the food allergy especially difficult. The results of the clinical, control and cohort studies to date stress a connection between impairments to the epidermal barrier and the shaping of a constitutional over-sensitivity. A precise mechanism of that phenomenon, however, has not been fully explained.

A team of American scientists, in a study on a mouse model with an impaired epidermal barrier function, observed the possibility to reach a state of transdermal sensitisation with ovalbumin, and then to develop a response by the respiratory system that was similar to asthma, resulting from administering ovalbumin in the form of an aerosol. Strid et al., in a study on a mouse model with an impaired epidermal barrier function, observed a correlation between a facilitated transdermal permeation of peanut and ovalbumin allergens and an allergic reaction in which the Th2 cells participated. The IL-4 secretion by the T cells of the lymph nodes and a high level of specific IgE and IgG1, with no $\operatorname{lgG} 2$, were noted. At the same time, it was observed in the study that an injection of the same allergens under the epidermis surface, directly to the dermis, resulted in a delayed allergic reaction that depended on the Th1 cells [43]. Impairing functions of the epidermal barrier in the mice accelerated maturing Langerhans cells 
(LC) characterised by the expression of MHC class II, CD86, CD40, CD54, and CD11c, but did not cause their migration. It was after exposing the mice to allergens that a fast migration of LC from the epidermis to the lymph nodes was obtained. The antigen presentation by the LC caused mostly Th2-cell-dependent response reactions. It was also noted that upon the occurrence of a transdermal allergisation, obtaining tolerance again was impossible when those allergens were administered orally $[30,43]$.

Observations carried out by some French scientists on a group of 27 five-month-old infants suffering from $A D$ indicate that it is possible to induce an allergy to almonds as a result of transdermal applications of almond oil onto the skin changed by the disease. An increased titre of specific lgE was observed in those infants, and their skin test provided positive results even though almonds had not been included in their diets. Additionally, the children's mothers had not consumed almonds when pregnant or breastfeeding [44]. Lack et al., in their cohort study, looked for an explanation of the phenomenon of developing an allergic reaction to peanuts in infants to whose diets peanuts had not been introduced. A possibility of developing the food allergy to peanuts in the foetal period, e.g. as a result of consuming food containing those allergens by a pregnant mother, was approached sceptically as no presence of the peanut-specific IgE in the cord blood of the neonates was observed.

However, in some infants the development of an IgE-dependent allergy to peanuts has been observed in spite of the fact that they were fed only with the milk of their mothers, whose diets did not contain peanuts either. The fact is that the mothers used peanut oil for taking care of their nipples in the period of breastfeeding, but as in preview reports [45] no correlation between such a procedure and the incidence of allergy to peanuts has been discovered in the breastfed infants. However, the scientists have noticed that some emollients that included unrectified peanut oil were used on those children. This made the team analyse the results obtained on the basis of some English cohort studies that included a group of 13,971 children in pre-school age. Forty-nine children in that group manifested symptoms of allergy to peanuts. Thirty-six children took part in the further study and in 29 of them the allergy to peanuts was confirmed based on skin tests, and in 23 children the allergy was confirmed on the basis of positive results of provocation tests. It has been observed that children whose treatment of atopic skin changes included emollients containing peanut oil manifested a higher risk of developing a food allergy to peanuts [46]. A prospective study carried out in a group of 302 French children showed that the application of emollients containing oat proteins entailed the allergy to oat in $32.5 \%$ of cases. During an oral provocation with oat flakes, the children manifested the symptoms from both digestive and respiratory systems [47].

However, the research into food allergies in the context of disturbances to the epidermal barrier does not account for the mechanisms of their occurrences. The need to continue the research in that field on larger populations, precisely diagnosed for food allergy, is stressed unanimously.

\section{The role of mutations in the FLG gene in the pathomechanism of food allergies}

The presence of mutations in the filaggrin-coding gene is the most frequently noted factor responsible for damaging the anatomical and functional barrier of the epidermis. There are reports showing a relation between mutations in the FLG gene and occurrences of a constitutional reaction to protein antigens in food. The results of clinical and control studies carried out by Brown et al. in a group of patients diagnosed with allergy to peanuts (71 patients of European origin, including: 35 British, 20 Irish, and 16 Dutch, as well as 390 patients from (anada) show a correlation between the presence and the type of mutation in the filaggrin-coding gene and the diagnosed allergy. An analysis of 71 patients originating from Europe, who were allergic to peanuts, has shown a strong and statistically significant connection between the occurrence of the allergy and a loss of function by filaggrin resulting from the R501X and 2282del4 mutations. An analysis of the results from 390 Canadian patients also confirmed this. Thus, it has been shown that a disturbance to the barrier function of the skin is a crucial risk factor in developing a food allergy to peanuts [19]. It is stressed, however, that food allergy and $A D$ are very similar phenotypically, and often a food allergy coexists with $A D$, so approaching them separately is difficult or even impossible. Thus, there is a need to diagnose food allergies precisely and to approach patients with allergic diseases in a comprehensive way.

An analysis of the relation between allergy to nickel and the presence of the R501X and 2282del4 mutations in the FLG gene, carried out on a Danish group of 3,471 people, confirmed such a dependency. In $25 \%$ of the patients diagnosed with a contact allergy to nickel a constitutional reaction was identified, including a reaction by the digestive system after consumption of nickel sulphate in food. In the case of a reaction by the digestive system, patients were advised to limit their consumption of such foods as chocolate, cocoa, soy, al- 
monds, and legumes. It was also observed in the study that the presence of an FLG gene mutation may be the cause of lowering the age at which the allergy induced by contact with nickel sulphate occurs. It has been also confirmed that the existence of a mutation in the FLG gene and body piercing at an early age may increase the risk of a more rapid allergic and inflammatory reactions induced by nickel haptens and may cause retention of those conditions in adult patients as well [48-50].

The scientific literature also includes reports on the absence of a connection between food or contact allergies and the aforementioned mutations in the FLG gene. The results of studies on the contact allergy to latex have not confirmed a statistically significant relation between the presence of the R501X and 2282del4 mutations in the FLG gene and higher predispositions to the contact allergy induced by any of the 13 identified protein allergens in latex. No cross-reaction to protein antigens in food has been noted in the studied group. However, due to the fact that the examined population was not large (20 people with symptoms of allergy to latex), the authors stressed the necessity to carry out the research on a more representative group of people [51]. No significant relation between food allergy to cow's milk proteins and mutations in the FLG gene has been confirmed in the studies on that condition either. However, a mutation in the FLG gene has been observed in patients who were diagnosed with $A D$ and an allergy to cow's milk at the same time. Further research has also been announced in that case [52].

\section{Summary}

The data provided in this publication draw attention to the complexity of the issue of allergic diseases. Transdermal permeation of allergens to the organism, including food allergens, may cause a state of over-sensitiveness and a fixed food allergy [53]. Therefore, further research aimed at learning the pathomechanisms of atopic diseases in the context of epidermal barrier function and the role of filaggrin are indispensable. There is a need for a comprehensive analysis of patients suffering from allergic diseases and their precise diagnosis. Particular attention should be paid to the issue of skin care in infants, both those suffering from allergic diseases and those in whom no pathologic changes or atopic manifestations in the skin have been observed. What may be a crucial factor in the pathomechanism of food allergy is contact of the damaged skin with food-originating allergens in emollients and cosmetics, and with allergens that may induce allergic cross-reactions in the future. The first allergic contact with a food allergen may happen even before a product suspected of allergenic potential is included into an infant's diet, which may increase the risk of atopy. Thus, knowledge of the pathomechanisms of allergic diseases and the role of filaggrin in that process may be very helpful in treating over-sensitivity.

\section{Acknowledgments}

The publication has been prepared within the project of the Ministry of Science and Higher Education: No. N N312 311939.

\section{References}

1. Asher MI, Montefort S, Björkstén B, et al. Worldwide time trends in the prevalence of symptoms of asthma, allergic rhinoconjunctivitis, and eczema in childhood: ISAAC Phases One and Three repeat multicountry cross-sectional surveys. Lancet 2006; 368: 733-43.

2. Svanes C. What has the ECRHS told us about the childhood risks of asthma, allergy and lung function? Clin Respir J 2008; 2 Suppl 1: 34-44.

3. Samoliński B, Raciborski F, Tomaszewska A, et al. Epidemiology of allergic diseases in Poland - ECAP study [Polish]. [Polish]. Alergoprofil 2008; 3940: 26-8.

4. Kabesch M, Schedel M, Carr D, et al. IL-4/IL-13 pathway genetics strongly influence serum IgE levels and childhood asthma. J Allergy Clin Immunol 2006; 117: 269-74.

5. Suttner K, Rosenstiel P, Depner M, et al. TBX21 gene variants increase childhood asthma risk in combination with $\mathrm{HLX} 1$ variants. J Allergy Clin Immunol 2009; 123: 1062-8.

6. Balaci L, Spada MC, Olla N, et al. IRAK-M is involved in the pathogenesis of early-onset persistent asthma. Am J Hum Genet 2007; 80: 1103-14.

7. Gudbjartsson DF, Bjornsdottir US, Halapi E, et al. Sequence variants affecting eosinophil numbers associate with asthma and myocardial infarction. Nat Genet 2009; 41: 342-7.

8. Yang IA, Fong KM, Holgate ST, et al. The role of Toll-like receptors and related receptors of the innate immune system in asthma. Curr Opin Allergy Clin Immunol 2006; 6: 23-8.

9. Yang IA, Fong KM, Zimmerman PV, et al. Genetic susceptibility to the respiratory effects of air pollution. Thorax 2008; 63: 555-63.

10. Van Eerdewegh P, Little RD, Dupuis J, et al. Association of the ADAM33 gene with asthma and bronchial hyperresponsiveness. Nature 2002; 418: 426-30.

11. Himes BE, Hunninghake GM, Baurley JW, et al. Genome-wide association analysis identifies PDE4D as an asthma-susceptibility gene. Am J Hum Genet 2009; 84: 581-93.

12. Soderhall C, Marenholz I, Kerscher T, et al. Variants in a novel epidermal collagen gene (COL29A1) are associated with atopic dermatitis. PLoS Biol 2007; 5: 242-54.

13. Holloway JW, Koppelman GH. Identifying novel genes contributing to asthma pathogenesis. Curr Opin Allergy Clin Immunol 2007; 7: 69-74.

14. Ober C, Tan Z, Sun Y, et al. Effect of variation in CHI3L1 on serum YKL-40 level, risk of asthma, and lung function. N Engl J Med 2008; 358: 1682-91. 
15. Sutherland TE, Maizels RM, Allen JE. Chitinases and chitinase-like proteins: potential therapeutic targets for the treatment of T-helper type 2 allergies. Clin Exp Allergy 2009; 39: 943-55.

16. Hawro T, Sysa-Jędrzejewska A, Narbutt J. The role of filaggrin gene mutations in pathogenesis of atopic dermatitis. Literature review [Polish]. Postep Derm Alergol 2008; 15: 12-5.

17. Kurowski M, Kowalski ML. Filaggrin and its role in the pathomechanism of allergic disease [Polish]. Alergia Astma Immunologia 2009; 15: 95-100.

18. Thyssen JP, Johansen JD, Linneberg A, et al. The association between null mutations in the filaggrin gene and contact sensitization to nickel and other chemicals in the general population. Br J Dermatol 2010; 162: 1278-85.

19. Brown SJ, Asai Y, Cordell HJ, et al. Loss-of-function variants in the filaggrin gene are a significant risk factor for peanut allergy. J Allergy Clin Immunol 2011; 127: 661-7.

20. Candi E, Schmidt R, Melino G. The cornified envelope: a model of cell death in the skin. Nat Rev Mol Cell Biol 2005; 6: 328-40.

21. Gan S, McBride O. Organization, structure, and polymorphisms of the human profilaggrin gene. Biochemistry 1990; 29: 9432-40.

22. Fleckman P, Brumbaugh S. Absence of the granular layer and keratohyalin define a morphologically distinct subset of individuals with ichthyosis vulgaris. Exp Dermatol 2002; 11: 327-36.

23. Sugiura $H$, Ebise $H$, Tazawa $T$, et al. Large scale DNA microarray analysis of atopic skin lesions show overexpression of an epidermal differentiation gene cluster in the alternative pathway and lack of protective gene expression in the cornified envelope. Br J Dermatol 2005; 152: 146-9.

24. Palmer CN, Irvine AD, Terron-Kwiatkowski A, et al. Common loss-of-function variants of the epidermal barrier protein filaggrin are a major predisposing factor for atopic dermatitis. Nat Genet 2006; 38: 441-6.

25. Brown SJ, Irvine AD. Atopic eczema and the filaggrin story. Semin Cutan Med Surg 2008; 27: 128-37.

26. Brown SJ, Relton CL, Liao H, et al. Filaggrin null mutations and childhood atopic eczema: a population-based case-contro study. J Allergy Clin Immunol 2008; 121: 940-6.

27. Zhang H, Guo Y, Wang W, et al. Mutations in the filaggrin gene in Han Chinese patients with atopic dermatitis Allergy 2011; 66: 420-7.

28. De Benedetto A, Qualia CM, Baroody FM, et al. Filaggrin expression in oral, nasal, and esophageal mucosa. J Invest Dermatol 2008; 128: 1594-7.

29. Ying S, Meng Q, Corrigan CJ, et al. Lack of filaggrin expression in the human bronchial mucosa. J Allergy Clin Immunol 2006; 118: $1386-8$

30. Strid J, Hourihane J. Kimber I, et al. Epicutaneous exposure to peanut protein prevents oral tolerance and enhances allergic sensitization. Clin Exp Allergy 2005; 35: 757-66.

31. Palmer CN, Ismail T, Lee SP, et al. Filaggrin null mutations are associated with increased asthma severity in children and young adults. J Allergy Clin Immunol 2007; 120: 64-8.

32. Van den Oord RA, Sheikh A. Filaggrin gene defects and risk of developing allergic sensitisation and allergic disorders: systematic review and meta-analysis. BMJ 2009; 339: b2433.

33. Henderson J, Northstone K, Lee S, et al. The burden of disease associated with filaggrin mutations: a population-based, lon- gitudinal birth cohort study. J Allergy Clin Immunol 2008; 121: 872-7.

34. Weidinger S, Rodriguez E, Stahl C, et al. Filaggrin mutations strongly predispose to early-onset and extrinsic atopic dermatitis. J Invest Dermatol 2007; 127: 724-6.

35. Weidinger S, O'Sullivan M, Illig T, et al. Filaggrin mutations, atopic eczema, hay fever, and asthma in children. J Allergy Clin Immunol 2008; 121: 1203-9.

36. Marenholz I, Nickel R, Rüschendorf F, et al. Filaggrin loss-offunction mutations predispose to phenotypes involved in the atopic march. J Allergy Clin Immunol 2006; 118: 866-71.

37. Kulig M, Bergmann R, Klettke $U$, et al. Natural course ofsensitization to food and inhalant allergens during the first 6 years of life. J Allergy Clin Immunol 1999; 103: 1173-9.

38. Hoffjan S, Nicolae D, Ober C, et al. Association studies for asthma and atopic diseases: a comprehensive review of the literature. Respir Res 2003; 4: 14-24.

39. Zheng $\mathrm{T}, \mathrm{Yu}$ J, $\mathrm{Oh} \mathrm{MH}$, et al. The atopic march: progression from atopic dermatitis to allergic rhinitis and asthma. Allergy Asthma Immunol Res 2011; 3: 67-73.

40. He R, Oyoshi MK, Jin H, et al. Epicutaneous antigen exposure induces a Th17 response that drives airway inflammation after inhalation challenge. Proc Natl Acad Sci U S A 2007; 104: 15817-22.

41. Oyoshi MK, Murphy GF, Geha RS. Filaggrin-deficient mice exhibit Th17-dominated skin inflammation and permissiveness to epicutaneous sensitization with protein antigen. J Allergy Clin Immunol 2009; 124: 485-93.

42. Spergel JM, Mizoguchi E, Brewer JP, et al. Epicutaneous sensitization with protein antigen induces localized allergic dermatitis and hyperresponsiveness to methacholine after single exposure to aerosolized antigen in mice. J Clin Invest 1998; 101: 1614-22.

43. Strid J, Hourihane J, Kimber I, et al. Disruption of the stratum corneum allows potent epicutaneous immunization with protein antigens resulting in a dominant systemic Th2 response. Eur J Immunol 2004; 34: 2100-9.

44. Callard RE, Harper JI. The skin barrier, atopic dermatitis and allergy: a role for Langerhans cells. Trends Immunol 2007; 28: 294-8.

45. Guillet G, Guillet MH. Percutaneous sensitization to almond oil in infancy and study of ointments in 27 children with food allergy. Allerg Immunol (Paris) 2000; 32: 309-11.

46. Lack G, Fox D, Northstone K, et al. Factors associated with the development of peanut allergy in childhood. N Engl J Med 2003; 348: 977-85.

47. Boussault P, Leaute-Labreze C, Saubusse E, et al. Oat sensitization in children with atopic dermatitis: prevalence, risks and associated factors. Allergy 2007; 62: 1251-6.

48. Scharschmidt TC, Man MQ, Hatano Y, et al. Filaggrin deficiency confers a paracellular barrier abnormality that reduces inflammatory thresholds to irritants and haptens. J Allergy Clin Immunol 2009; 124: 496-506.

49. Ross-Hansen K, Menné T, Johansen JD, et al. Nickel reactivity and filaggrin null mutations-evaluation of the filaggrin bypass theory in a general population. Contact Dermatitis 2011; 64: 24-31. 
50. Novak N, Baurecht H, Schafer T, et al. Loss-of-function mutations in the filaggrin gene and allergic contact sensitization to nickel. J Invest Dermatol 2008; 128: 1430-5.

51. Carlsen BC, Meldgaard M, Hamann D, et al. Latex allergy and filaggrin null mutations. J Dent 2011; 39: 128-32.

52. Savilahti EM, Ilonen J, Kiviniemi M, et al. Human leukocyte antigen (DR1)-DQB1*0501 and (DR15)-DQB1*0602 haplotypes are associated with humoral responses to early food allergens in children. Int Arch Allergy Immunol 2010; 152: 169-77.

53. Fallon PG, Sasaki T, Sandilands A, et al. A homozygous frameshift mutation in the mouse FLG gene facilitates enhanced percutaneous allergen priming. Nat Genet 2009; 41: 602-8.

Received: 25.01 .2012

Accepted: 5.12 .2012 